\title{
Experimental Study of the Fire Mass Loss Rate in Confined and Mechanically Ventilated Multi-Room Scenarios
}

\author{
W. LE SAUX, H. PRETREL, C. LUCCHESI and P. GUILLOU \\ Laboratoire d'Expérimentation des Feux (DPAM/SEREA/LEF) \\ Institut de Radioprotection et de Sûreté Nucléaire (IRSN) \\ Centre de Cadarache, BP N³, 13115 Cédex, St Paul-lez-Durance - FRANCE
}

\begin{abstract}
This paper presents an experimental study of the behaviour of the mass loss rate (MLR) of pool fires in mechanically ventilated compartments within the framework of fire research activities conducted at the French Institute for Radiological Protection and Nuclear Safety (IRSN). Two typical scenarios are investigated: the 1-room configuration and the 2-rooms configuration with an open doorway between the two rooms. This study is based on full scale tests carried out as part of the international OECD PRISME project (OECD: Organisation for Economic Co-operation and Development; PRISME: French acronym for "Fire Propagation in Elementary Multi-room Scenarios"). First the behaviours of the MLR for the two scenarios are presented independently. A comparison is then proposed that highlights the effect of the air change rate on the MLR. The analysis shows that the MLR depends on two effects: the oxygen concentration and a blowing effect towards the pool. For most tests, the effect of oxygen concentration is predominant and the MLR varies linearly with the change of oxygen concentration. For one test with the 2rooms scenario, the air flow at the door seems to induce higher oxygen level adjacent to the pool and the MLR is identical to that in the open air, albeit with an oxygen concentration below $21 \% \%_{\mathrm{vol}}$; In this configuration, the air flow at the door may induce not only a locally higher oxygen level, but also a blowing effect that stokes the fire. This large-scale test campaign shows that the air flow around the pool is also an important parameter to predict the MLR.
\end{abstract}

KEYWORDS: pool fire, burning rate, ventilation, nuclear safety, compartment fire, doorway

NOMENCLATURE LISTING

$\begin{array}{llll}1 R & \text { One room } & \text { Subscripts: } & \\ 2 R & \text { Two rooms } & * & \text { Dimensionless parameter } \\ m & \text { Mass }(\mathrm{g}) & \circ & \text { Open air, free atmosphere } \\ M L R & \text { Mass loss rate }\left(\mathrm{g} \cdot \mathrm{s}^{-1}\right)=\mathrm{dm} / \mathrm{dt} & d & \text { Doorway } \\ Q & \text { Volumetric flow rate }\left(\mathrm{m}^{3} \cdot \mathrm{h}^{-1}\right) & \text { in } & \text { Inlet } \\ t & \text { Time }(\mathrm{s}) & \text { lim } & \text { Limit } \\ T r & \text { Air change rate }\left(\mathrm{h}^{-1}\right) & m & \text { Mean } \\ U & \text { Velocity }\left({\left.\mathrm{m} . \mathrm{s}^{-1}\right)}^{3}\right. & \mathrm{O} 2 & \text { Oxygen } \\ V & \text { Volume }\left(\mathrm{m}^{3}\right) & v & \text { Ventilation } \\ X & \text { Molar }(\text { or volume }) \text { concentration }\left(\% \mathrm{vol}_{\mathrm{vl}}\right) & & \\ z & \text { Height }(\mathrm{m}) & & \end{array}$

\section{INTRODUCTION}

An important fire safety issue in the nuclear industry is the smoke propagation in a confined and mechanically ventilated compartment. Key information for addressing fire safety assessment is the knowledge of the burning rate. For most confined configurations, the burning rate is closely dependant on the environment and especially on the composition of the air around the fire, the motion of air and the radiation feedback towards the fire.

This issue is currently investigated at the French "Institut de Radioprotection et de Sûreté Nucléaire" $\left(\mathrm{IRSN}^{1}\right)$ at small and large scales. This study provides new information regarding the behaviour of the mass loss rate and focuses particularly on the comparison between the behaviour of a liquid pool fire in open-air, 1-room and 2-rooms tests as illustrated in Fig. 1.

Many studies have been performed for the open-air pool fire scenario. The confined and ventilated 1-room scenario is also quite well documented although for ventilated combustion regimes, the global behaviour of the fire remains complex and many areas need further research, such as extinction, combustion instabilities, 
the influence of soot, the influence of the fire location, etc. The 1-room scenario with an open door is also a configuration that has been thoroughly investigated: the flow at the doorway (Zukoski [1], Nakaya [2]), the position of the fire and the shape of opening (Parkes and Fleischmann [3]), the impact of the ventilation. Numerous small and large-scale tests have been carried out. The bi-directional flow at the doorway has been investigated in depth (Bryant [4]) as has the feedback effect on the fire mass loss rate (Utiskul [5]) or the global energy balance (Hamins [6], Bundy [7]). Fewer studies have been carried out for 2-rooms scenarios involving two confined and mechanically ventilated rooms and very few published papers are available. However, for nuclear safety in particular, and for the industry in general, it is a widespread configuration that requires further study.

This study deals with the scenario of two mechanically ventilated, closed rooms with an open connecting doorway with particular emphasis on the mass loss rate. The study is based on full-scale pool fire tests representative of compartment fire scenarios in the nuclear industry and with fire heat release rates varying between $150 \mathrm{~kW}$ and $900 \mathrm{~kW}$. These tests have been performed within the framework of the international OECD PRISME project. The methodology proposed is to investigate the 2-rooms fire scenarios based on a comparison with open-air and 1-room scenarios (Pretrel [8]).

The paper comprises four sections. First, details are given of the test facility, its instrumentation and the tests performed. The mass loss rates for 1-room and 2-rooms scenarios are then described separately. A comparison between the two scenarios is then proposed, focusing on variations with time, the effect of the oxygen concentration and the air change rate. Finally, the relation between oxygen concentration and mass loss rate is discussed.

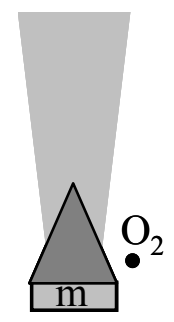

(a)

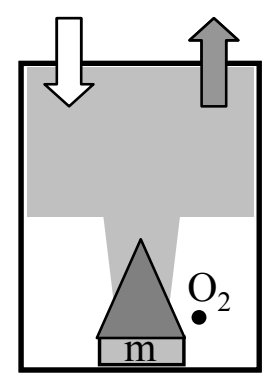

(b)

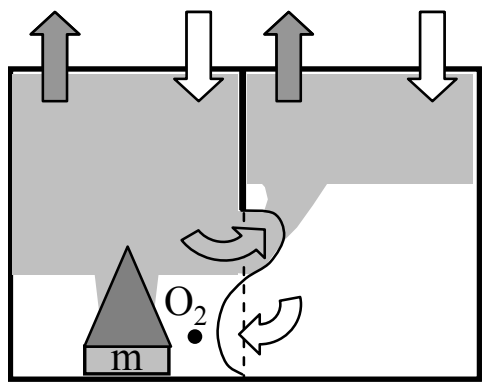

(c)

Fig. 1. Schematic representation of test configurations: open air (a), 1-room (b) and 2-rooms (c)

\section{DESCRIPTION OF THE EXPERIMENTS}

\section{Experimental Facilities}

Three sets of tests are considered: open air, 1-room and 2-rooms. Open air tests were performed under a $3 \mathrm{~m}$ diameter hood (Fig. 2) in the IRSN-SATURNE facility $\left(2000 \mathrm{~m}^{3}\right)$ which is open to the outside air. Compartment tests were performed in the IRSN-DIVA facility (Fig. 3), a large scale multi-room facility comprising four rooms (labelled 1 to 4 ) and a corridor with $0.3 \mathrm{~m}$ thick reinforced concrete walls and equipped with a mechanical ventilation system. The facility is used in 1-room (Fig. 4) and 2-rooms (Fig. 5) test configurations with the fire at the centre of the fire room. Inlet and exhaust ducts are situated in the upper part of each room, near the ceiling as shown in the figures. For the 2-rooms configuration, an open door $(2.1 \mathrm{~m}$ high by $0.7 \mathrm{~m}$ wide) is located at the centre of the wall.

\section{Metrology}

Variables considered in this analysis are the mass loss rate, the oxygen concentrations within the fire room and the volumetric air flows.

For the three sets of tests, the mass loss rate is deduced from an electronic balance (SARTORIUS; $0-300 \mathrm{~kg} ; \pm 2 \mathrm{~g}$ ) that measures the mass of the burning pool on line.

Oxygen molar (or volume) concentration inside the fire room was measured continuously by gas analysers at three locations: near the pool and in the upper and the lower part of the compartment (see Fig. 4 and Fig. 5 for locations). Paramagnetic gas analysers (SERVOMEX) were used. 
In the inlet and exhaust pipes of the ventilation network, the volume flow rates were obtained by average bi-directional probes (ANNUBAR type) connected to pressure transducers (ROSEMOUNT type).

For the 2-rooms configuration, fourteen bi-directional probes (McCaffrey [9]) were installed in the centre of the doorway (see Fig. 6 and Fig. 7) and connected to pressure transducers (FURNESS CONTROLS) to measure gas velocity. The flow rate of the gases through the doorway was then determined from the measured velocities using the integral trapezoidal rule, knowing the height between sensors, the width of the door opening and assuming the velocities to be virtually uniform over the entire width of the doorway.

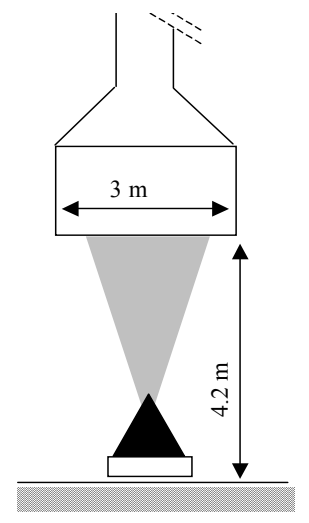

Fig. 2. Schematic representation of the SATURNE hood

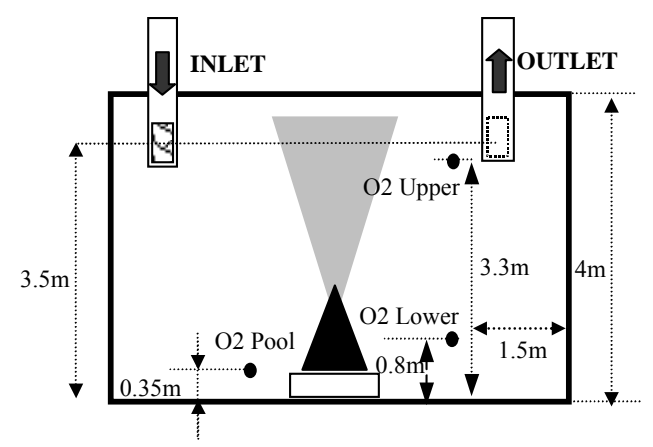

Fig. 4. Schematic representation of the 1-room configuration in the DIVA facility

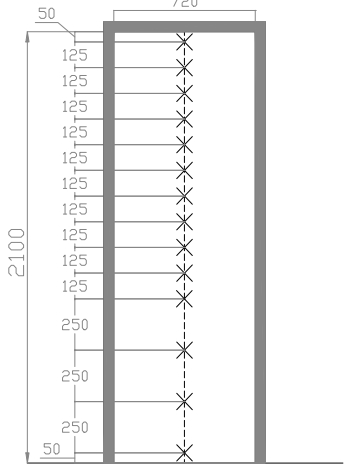

Fig. 6. Doorway velocity probe arrangement for the 2-rooms configuration

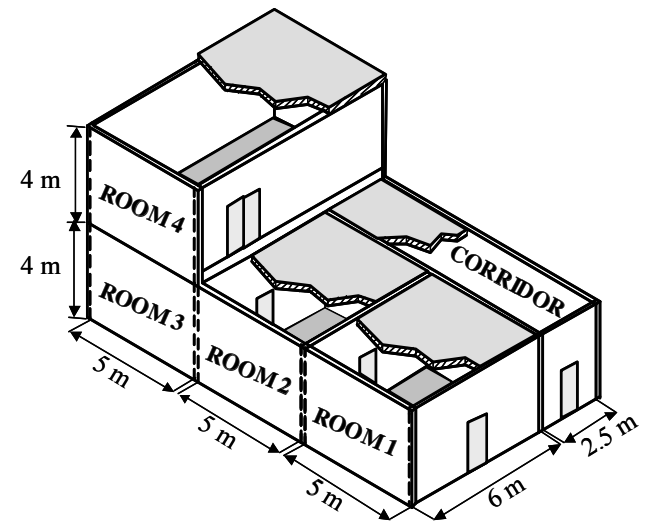

Fig. 3. Schematic representation of the DIVA facility

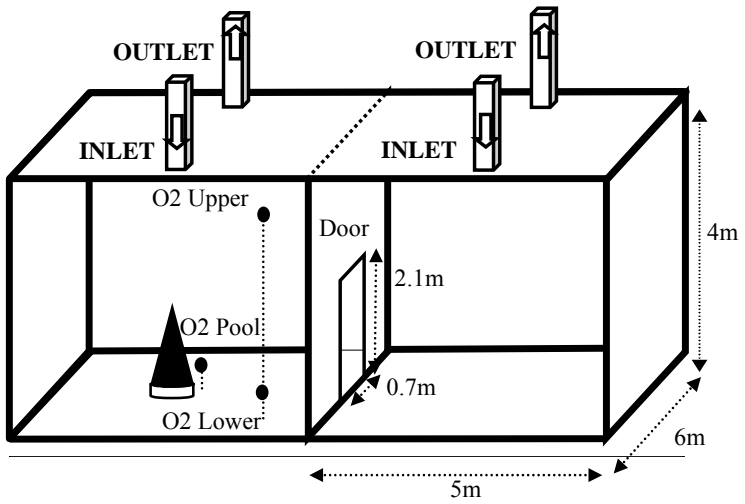

Fig. 5. Schematic representation of the 2-rooms configuration in the DIVA facility

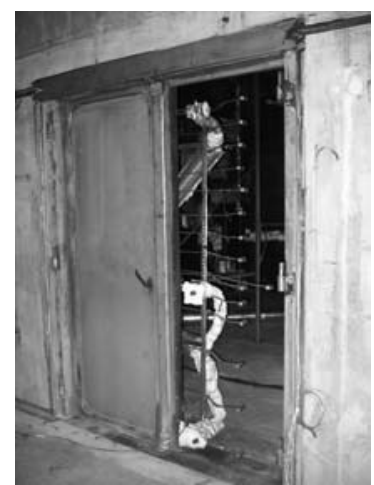

Fig. 7. Photograph of the doorway velocity probes for the 2-rooms configuration

\section{Fire}

The fire consisted of a circular container (10cm deep) filled with liquid fuel called TPH for Hydrogenated Tetra-Propylene $\left(\mathrm{C}_{12} \mathrm{H}_{26}\right)$, a fuel used for nuclear reprocessing (similar to dodecane fuel). The container 
was placed on a weighing device, $0.4 \mathrm{~m}$ above ground level. All tests were performed using the same size of circular pool $\left(0.4 \mathrm{~m}^{2}, \mathrm{D}=0.714 \mathrm{~m}\right)$.

\section{Test Procedure and Test Grid}

The main test characteristics are given in Table 1 . The ventilation rate or air change rate (labelled $\operatorname{Tr}$ in $\mathrm{h}^{-1}$ ) is defined as the ratio between the ventilation airflow rate before ignition divided by the room volume $\left(120 \mathrm{~m}^{3}\right)$. The air change rate of $0 \mathrm{~h}^{-1}$ used for the 2-rooms test $2 \mathrm{R}$ Tr $=0$ means that the fire room is not ventilated and that the inlet duct in the adjoining room is closed whereas the outlet duct remains open. During the fire, the airflow at the outlet duct is controlled by natural convection. For the other 2-rooms tests, the same air change rate is applied to both rooms.

The procedure adopted for compartment tests is as follows: the room ventilation rate(s) is (are) first set to the required condition ( $\operatorname{Tr}$ value). The fuel is then ignited with a propane burner, in the same way as for tests under the hood. The pool fire burns until extinction occurs either due to either lack of fuel or oxygen within the enclosure.

Table 1. Tests characteristics

\begin{tabular}{|l|c|c|}
\hline Test name & Number of room(s) & Tr \\
\hline Free atm. & - & - \\
\hline 1R_Tr=1.5 & 1 & 1.5 \\
\hline 1R_Tr $=4.7$ & 1 & 4.7 \\
\hline 1R_Tr=8.4 & 1 & 8.4 \\
\hline 2R_Tr=0 & 2 & 0 \\
\hline 2R_Tr=1.5 & 2 & 1.5 \\
\hline 2R_Tr=4.7 & 2 & 4.7 \\
\hline 2R_Tr $=8.6$ & 2 & 8.6 \\
\hline
\end{tabular}

In the following sections, the analysis of the MLR and the oxygen concentration are considered as dimensionless variables. The dimensionless MLR is the MLR divided by the maximum amplitude obtained in an open atmosphere. The dimensionless oxygen concentration is expressed as $\left(\mathrm{X}_{\mathrm{O} 2}-\mathrm{X}_{\mathrm{O} 2 \text {-lim }}\right) /\left(\mathrm{X}_{\mathrm{O} 2}{ }^{\circ}-\mathrm{X}_{\mathrm{O} 2 \text {-lim }}\right)$ where $\mathrm{X}_{\mathrm{O} 2 \text {-lim }}$ is the oxygen concentration limit for $\mathrm{TPH}$ and $\mathrm{X}_{\mathrm{O} 2}{ }^{\circ}$ is the concentration in the open air.

\section{MASS LOSS RATE IN 1-ROOM TESTS}

\section{Variation with Time}

The mass loss rate versus time curve for 1-room tests shows three successive stages: an initial, transitory phase, a stationary phase and an extinction phase. Fig. 8 shows the dimensionless MLR versus time for the three 1-room tests compared to the MLR in the open air.

The transitory phase comprises two main sub-phases: the first with a MLR behaviour very similar to that in an open atmosphere and the second having a peak burning rate which is due to the particular flow motion near the flame. This transitory period is explained by rapid changes of the gas properties within the room due, in particular, to the gradual build-up of smoke within the room associated with oxygen depletion (Pretrel [8]). During the second, stationary phase, the MLR remains constant. For the lowest level of air change rate $\left(\mathrm{Tr}=1.5 \mathrm{~h}^{-1}\right)$, extinction occurs at the end of the transitory phase and no stationary phase is observed. The MLR level during this stationary phase is definitely lower than the expected level in the open air. The final phase is the extinction phase that occurs either through lack of fuel (test with $\operatorname{Tr}=4.7 \mathrm{~h}^{-1}$ ) or lack of oxygen (test with $\operatorname{Tr}=1.5 \mathrm{~h}^{-1}$ ).

\section{Oxygen Distribution within the Fire Room}

An important variable for analyzing MLR behaviour is the oxygen concentration within the room. Fig. 9, Fig. 10, and Fig. 11, show the oxygen concentration near the pool, in the upper and in the lower part of the room. As expected, the oxygen concentration decreases during combustion and the three probes follow the same trends. However, closer observation shows a variation in oxygen concentrations within the room. 
During the transitory phase at the beginning of the fire, the probe in the upper part of the room is the first to detect the oxygen consumption, followed by the probe in the lower part and the probe close to the pool. During the stationary phase, the oxygen concentrations near the pool and in the lower part are very similar. The concentration in the upper part is always slightly lower.

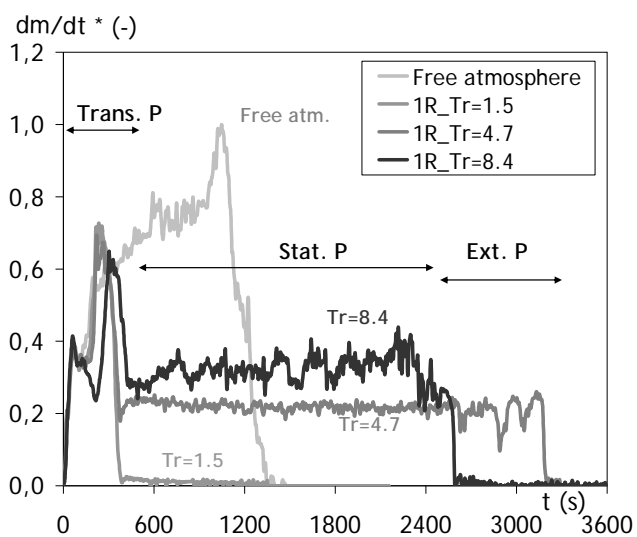

Fig. 8. Mass loss rate versus time for 1-room configuration.

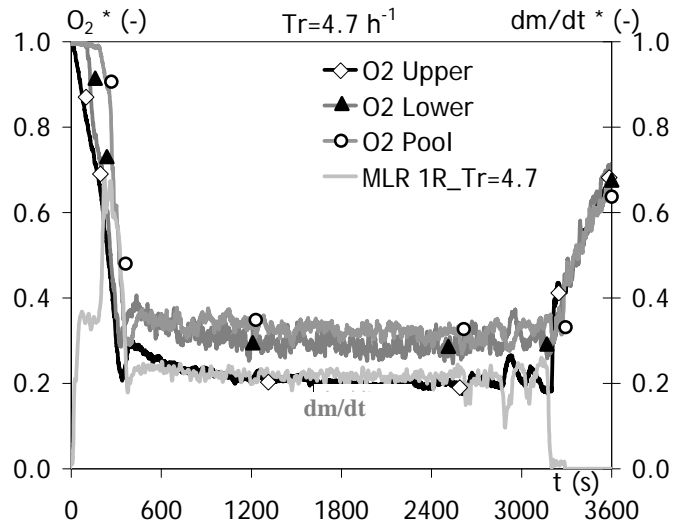

Fig. 10. Mass loss rate and oxygen concentrations for 1-room configuration $\left(\mathrm{Tr}=4.7 \mathrm{~h}^{-1}\right)$.

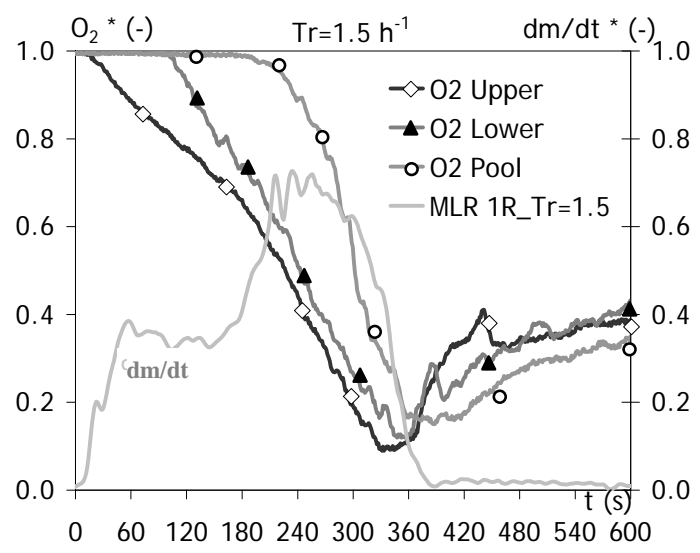

Fig. 9. Mass loss rate and oxygen concentrations for 1-room configuration $\left(\mathrm{Tr}=1.5 \mathrm{~h}^{-1}\right)$.

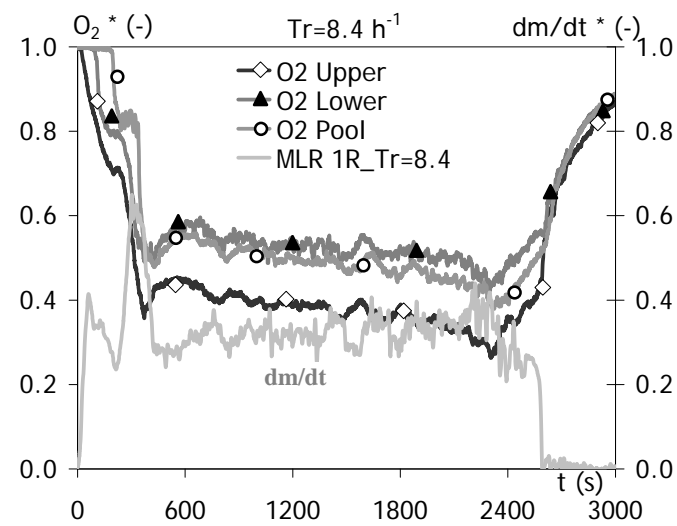

Fig. 11. Mass loss rate and oxygen concentrations for 1-room configuration $\left(\mathrm{Tr}=8.4 \mathrm{~h}^{-1}\right)$.

\section{Effect of the Air Change Rate}

The air change rate modifies the MLR. The main effect is the change of the MLR level during the stationary phase. The higher the air change rate, the higher the MLR. Nevertheless, for the range of air change rates investigated, which is representative of the actual conditions encountered in nuclear power plants, the average MLR during the stationary phase remains much lower than that in the open air. For air change rate of $8.4 \mathrm{~h}^{-1}$, the mean MLR is approximately $40 \%$ of the MLR in the open air.

\section{MASS LOSS RATE IN 2-ROOMS TESTS}

\section{Variation with Time}

The Fig. 12 shows the MLR versus time for the four 2-rooms tests and the open-air test.

As shown in Fig. 13 for test $2 \mathrm{R}$ _ Tr=4.7, the mass loss rate versus time in 2-rooms tests also shows three successive stages corresponding to the transitory phase, a steady-state phase and the extinction phase. 


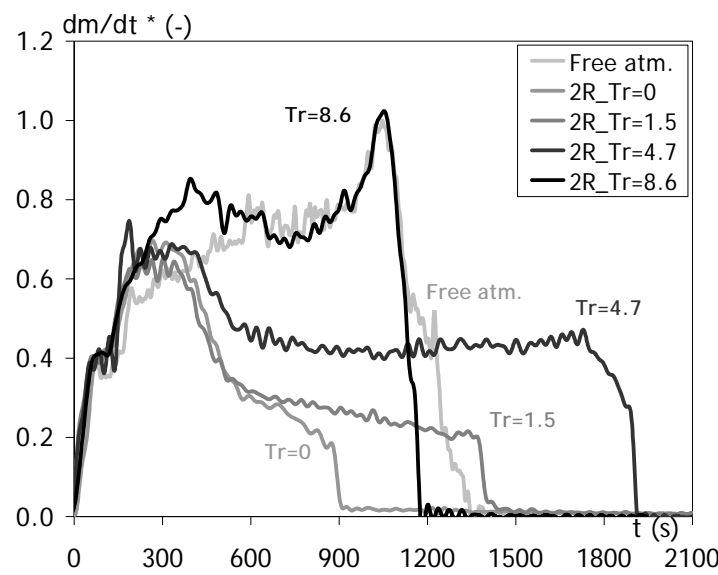

Fig. 12. Mass loss rate versus time for 2-rooms configuration.

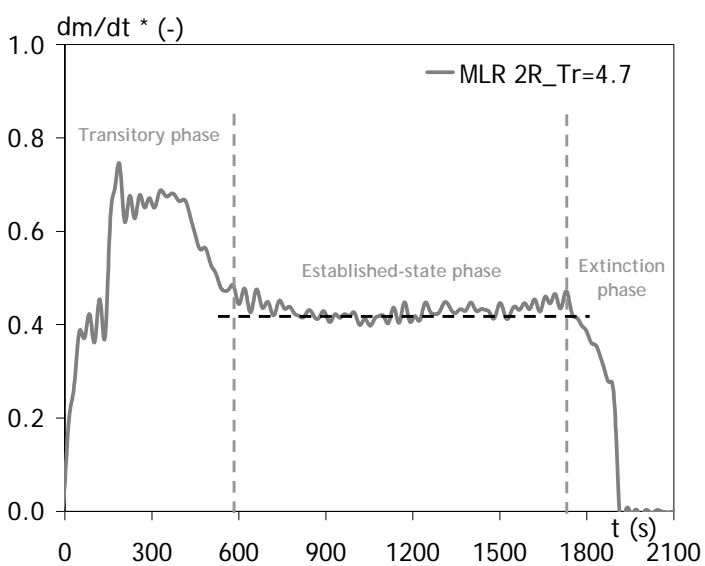

Fig. 13. The various phases of MLR variation with time.

During the transitory phase, sub-phases are identified. First, two successive fast increases of the mass loss rate are observed. These periods correspond to the flame propagation over the pool, and the build-up in the room of hot gases and smoke. The durations of these two sub-phases were easily established from the videos taken during the tests. These sub-phases are nearly the same as those already described in open-air and 1-room configuration tests. A small increase of the mass loss rate is then observed. This period corresponds to the onset of the spread of smoke through the doorway and into the upper zone in the adjacent room. The mass loss rate then peaks. During this period, room 1 and room 2 smoke interfaces are located at the same height and the two rooms behave as a single, continuously smoke-filled room.

Following the unsteady-state phase, the steady-state phase is characterized by a constant variation of the mass loss rate with time. Depending on the test configuration, three types of variation are identified (see Fig. 12).

The first type is a constant decrease of MLR, as obtained during tests $2 \mathrm{R} \_\mathrm{Tr}=0$ and $2 \mathrm{R} \_\mathrm{Tr}=1.5$. The second type of MLR variation corresponds to a steady regime during which the MLR remains almost constant as observed in test $2 \mathrm{R} \_\mathrm{Tr}=4.7$. The third type is a constant increase of the MLR as observed in test 2R_Tr=8.6.

In each case, the steady-state phase is followed by a rapid decrease of the mass loss rate until the fire stops, except for test $2 \mathrm{R} \_\mathrm{Tr}=8.6$ where a significant MLR peak was noted during the last pre-extinction period. This behaviour is explained by the thermal balance of the fuel within the pan. The heat absorbed by the steel tank and the low quantity of fuel remaining leads to a very high rate of fuel vaporization.

Extinction of the fire occurred due to lack of oxygen for tests $2 \mathrm{R} \_\mathrm{Tr}=0$ and $2 \mathrm{R} \_\mathrm{Tr}=1.5$ and due to lack of fuel for tests $2 R_{-} \operatorname{Tr}=4.7$ and $2 R_{-} \mathrm{Tr}=8.6$, for which the level of ventilation was sufficient to maintain an adequate oxygen concentration level for combustion.

\section{Oxygen Distribution within the Fire Room}

As for the 1-room configuration, MLR and oxygen concentrations in three different locations of the fire room are plotted versus time for each test in Fig. 14 to Fig. 17.

As observed for the 1-room configuration, the oxygen concentrations decrease continuously during the fire. In addition, the distribution of oxygen within the rooms shows two different behaviours. The first behaviour (tests $2 \mathrm{R} \_\mathrm{Tr}=0,2 \mathrm{R} \_\mathrm{Tr}=1.5$ and $2 \mathrm{R} \_\mathrm{Tr}=4.7$ ) shows a uniform distribution in the lower part of the room (O2_Pool and $\mathrm{O}_{2}$ Lower are almost equal). The second behaviour (test $2 \mathrm{R} \_\mathrm{Tr}=8.6$ ) shows a heterogeneous distribution in the lower part. The concentrations near the pool and in a corner of the room are different. 


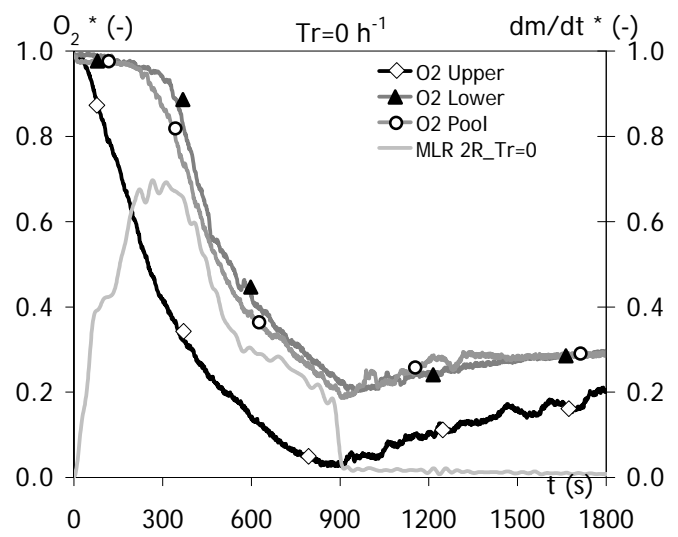

Fig. 14. Mass loss rate and oxygen concentrations versus time for test $2 \mathrm{R} \_\mathrm{Tr}=0$.

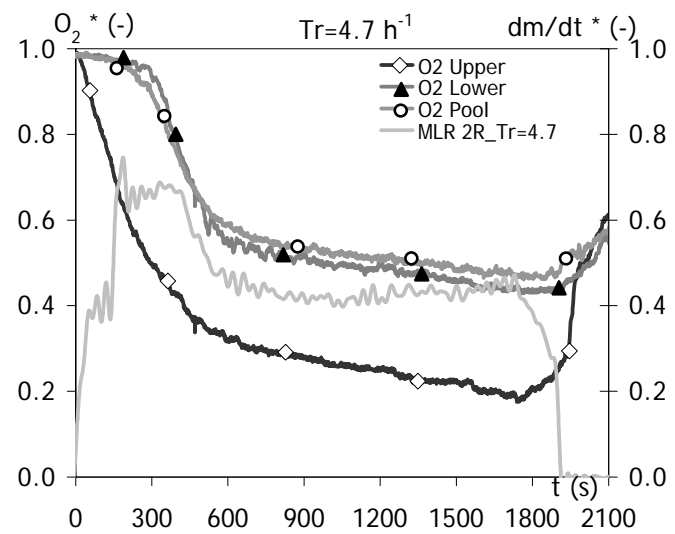

Fig. 16. Mass loss rate and oxygen concentrations versus time for test $2 \mathrm{R} \_\mathrm{Tr}=4.7$.

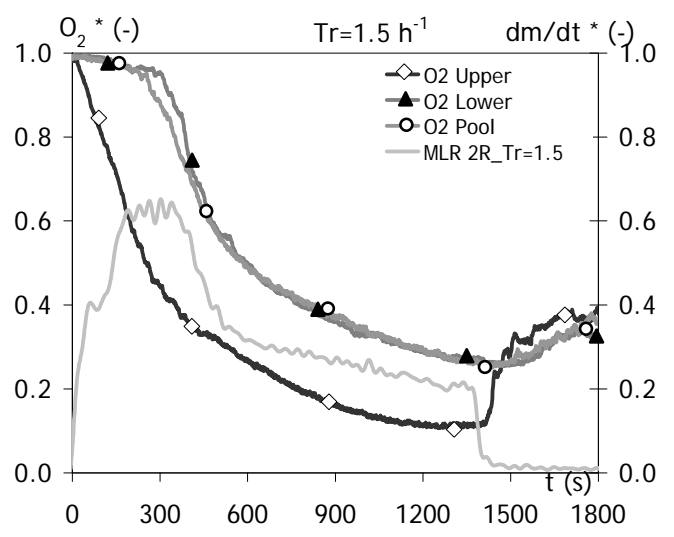

Fig. 15. Mass loss rate and oxygen concentrations versus time for test $2 \mathrm{R} \_\mathrm{Tr}=1.5$.

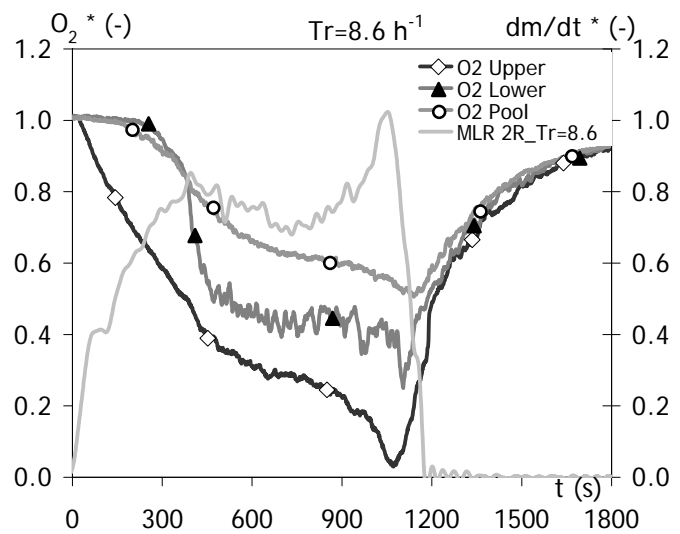

Fig. 17. Mass loss rate and oxygen concentrations versus time for test $2 \mathrm{R} \_\mathrm{Tr}=8.6$.

\section{Effect of the Velocities at the Doorway}

Fig. 18 shows a representative example of the velocity profiles for the bi-directional probes located in the centre of the doorway for each 2-rooms test 700s after ignition. This time is indicated in Fig. 19 where the mean velocities are plotted versus time.

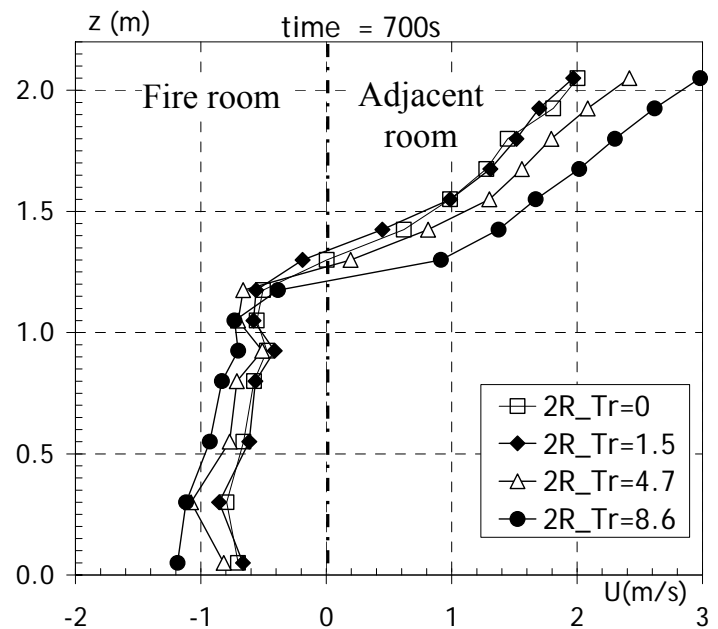

Fig. 18. Velocity profiles in the centre of the doorway for each 2-room test at $\mathrm{t}=700 \mathrm{~s}$

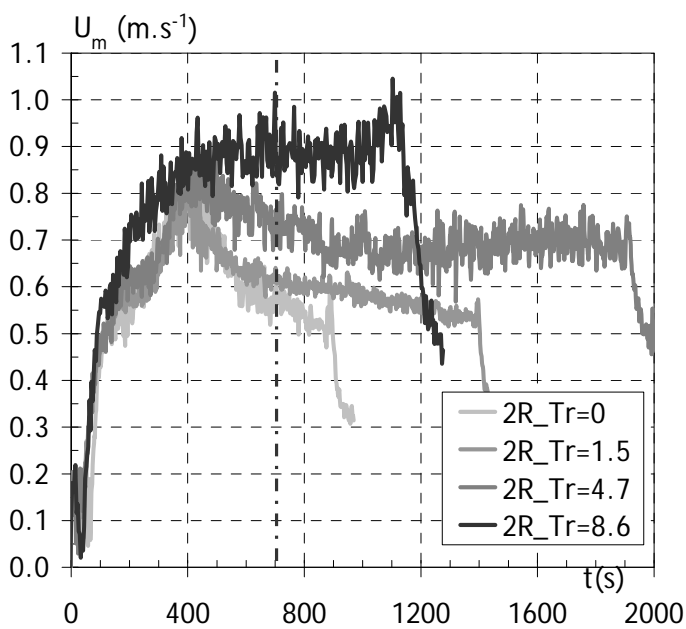

Fig. 19. Mean velocities versus time in the centre of the doorway for each 2-room test 
The velocity profiles of all tests show the same behaviour. The height of the flow entering the fire room from the adjacent room is about $1.25 \mathrm{~m}$, which is more than half of the door height. The velocities increase slightly from the flow interface to the ground.

The effect of the air change rate is significant. During the steady-state phase, it does not affect the shape of the profile but modifies the amplitude of the velocity: the higher the air change rate, the higher the velocity. The mean velocity varies from $0.5 \mathrm{~m} . \mathrm{s}^{-1}$ to $1 \mathrm{~m} \cdot \mathrm{s}^{-1}$. The increase of the air change rate modifies the heat release rate and consequently favours the incoming flow through the doorway.

\section{Effect of the Air Change Rate}

The effect of the air change rate is observed in Fig. 12. At the beginning of the transitory phase $(t \approx 4 \mathrm{~min})$, all MLRs are increasing together, showing that, during this time, the air-change rate does not have any influence on the MLR and so, the filling of the room 2 is unaffected by the air change rate.

Then, during the steady-state period, the air change rate alters the MLR. Two effects are noted. The first is an influence on the MLR amplitude: the higher the air change rate, the higher the MLR. The second effect is an influence on the variation of the MLR with time. For the two lowest air change rates $\left(0\right.$ and $\left.1.5 \mathrm{~h}^{-1}\right)$, the MLR decreases steadily until extinction due to lack of oxygen. For the intermediate air change rate $\left(4.7 \mathrm{~h}^{-1}\right)$, the MLR is constant, as for the 1-room scenario. As far as the highest air change rate is concerned $\left(8.4 \mathrm{~h}^{-1}\right)$, the MLR increases in the same way as in the open air.

It would appear that tests $2 \mathrm{R} \_\mathrm{Tr}=0$ and $2 \mathrm{R} \_\mathrm{Tr}=1.5$ were in under-ventilated conditions (decrease of the MLR and extinction through lack of oxygen). Test $2 \mathrm{R} \_\mathrm{Tr}=4.7$ corresponds to an equilibrium state between consumption of oxygen by combustion and the input of oxygen from the ventilation system and from the doorway. For test $2 \mathrm{R}_{-} \mathrm{Tr}=8.6$, the high air-change rate allows the extraction of a large quantity of combustion products coupled with a higher oxygen concentration in the gases coming through the lower part of the open door to the fire $(\mathrm{O} 2 \mathrm{Pool} * \approx 0.63)$.

\section{COMPARISON BETWEEN 1-ROOM AND 2-ROOMS SCENARIOS}

The effect of the type of scenario on the MLR is investigated by comparing the two scenarios analyzed separately in the previous sections. Only two air change rates are considered as they represent two typical phenomena: the medium value $\operatorname{Tr}=4.7 \mathrm{~h}^{-1}$ and the highest value $\operatorname{Tr} \sim 8.5 \mathrm{~h}^{-1}$ (average between 8.6 and 8.4). This comparison is based on the analysis of three sets of data: the MLR (see Fig. 20 and Fig. 21), the oxygen concentrations (see Fig. 22 and Fig. 23) and the volumetric air flow entering the fire room (see Fig. 24 and Fig. 25).

\section{Air Change Rate of $4.7 \mathrm{~h}^{-1}$}

First, the general trends of the MLR in 1-room or 2-rooms scenarios are similar. Three stages are detected: the transitory phase, the steady-state phase and the extinction phase. During the initial transitory phase, the behaviours of the MLR in both scenarios (1-room and 2-rooms) are very similar and the amplitude of the MLR is very near to the levels measured in the open air. The fact that the fire is located within one or two rooms has no influence at this stage of the fire. Changes in MLR then appear during the steady-state phase. The MLR in the 1-room scenario is two times lower than that in the 2-rooms scenario. Both are much lower than the level estimated in the open air. This difference in MLR amplitude affects the duration of the fire, since the amount of fuel is the same for the 3 tests.

In order to explain the behaviour of the MLR, the oxygen concentration within the fire room is analyzed. The oxygen concentration shows an opposite behaviour to that of the MLR. It decreases during the initial transitory phase and then remains approximately constant during the steady-state phase. Also, in both scenarios, the oxygen concentration is nearly uniform in the lower part of the room; the amplitudes of the two probes, near the pool and in one corner of the room, are very similar.

The volumetric air flows entering the fire room are also compared. For the 1-room scenario, the air flow into the room comes from the ventilation inlet duct. For the 2-rooms scenario, the air flow entering the fire room has two sources: the flow from the inlet duct and the flow entering through the open doorway. 

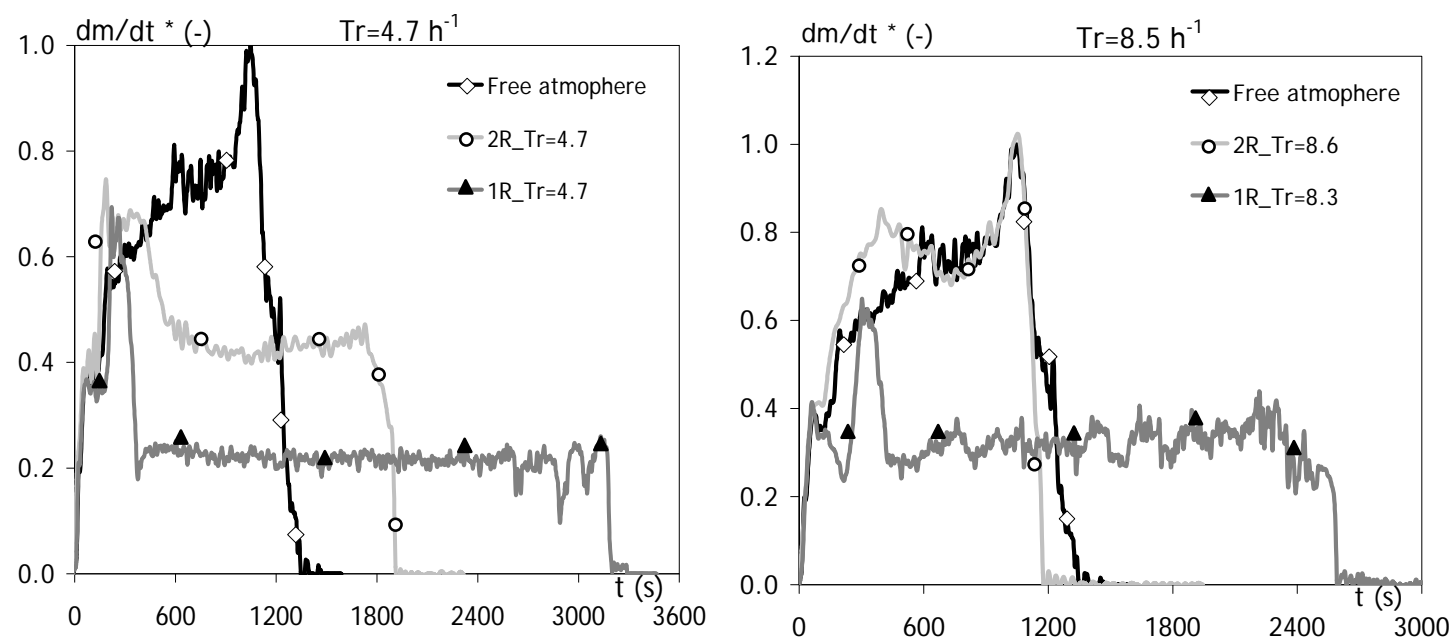

Fig. 20. Mass loss rates for open air and $\mathrm{Tr}=4.7$.

Fig. 21. Mass loss rates for open air and $\operatorname{Tr}=8.5$.
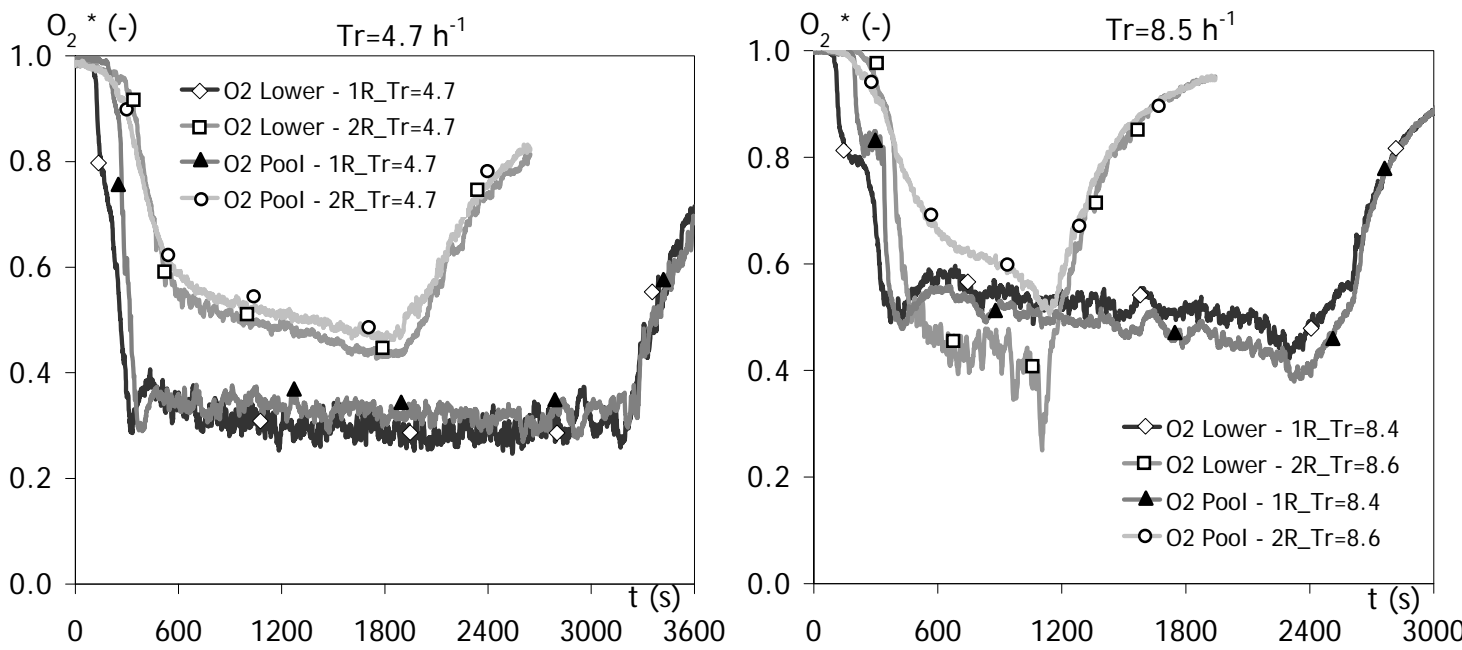

Fig. 22. Oxygen concentrations for $\mathrm{Tr}=4.7$.

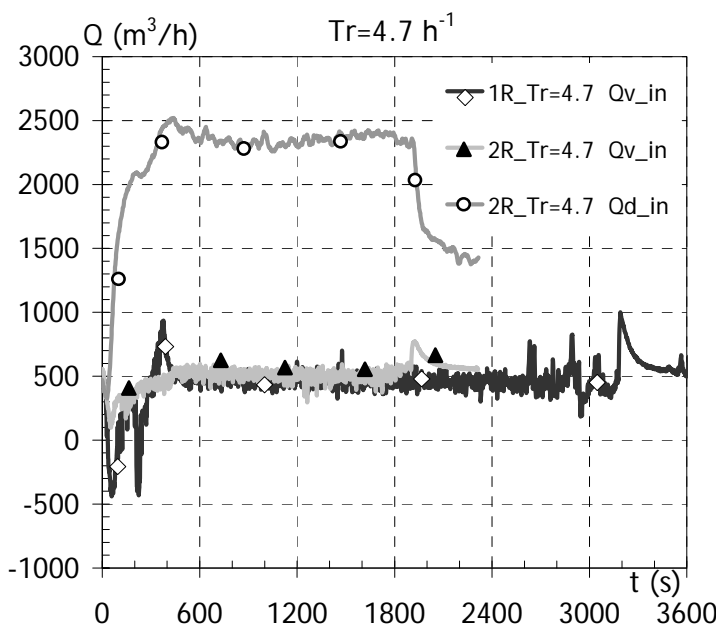

Fig. 24. Air flow rates for $\operatorname{Tr}=4.7$.
Fig. 23. Oxygen concentrations for $\mathrm{Tr}=8.5$.

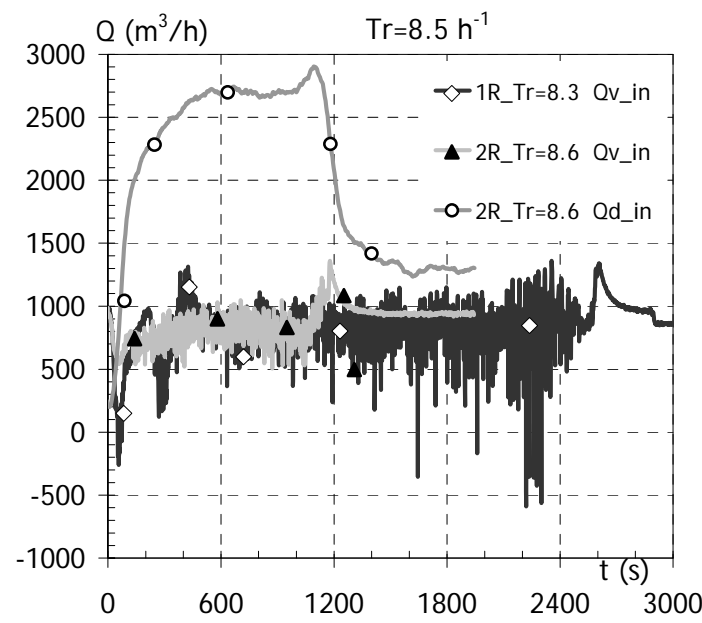

Fig. 25. Air flow rates for $\operatorname{Tr}=8.5$.

For the two scenarios, the air flow in the inlet duct is very similar, approximately $500 \mathrm{~m}^{3} / \mathrm{h}$ (as would be expected since the two tests are run at the same initial air change rate, $4.7 \mathrm{~h}^{-1}$ ). For the 2-rooms scenario, the additional contribution coming from the doorway has at least the same efficiency. With an incoming air 
flow of about $2400 \mathrm{~m}^{3} \cdot \mathrm{h}^{-1}$ at the door, a characteristic time of 3 minutes is estimated to exchange the volumes between the rooms. The contribution of the incoming flow from the adjoining room is then similar to that of the direct air supply into the fire room.

From these data, the change of the MLR amplitude is attributed to the effect of the oxygen concentration within the room, which is controlled by the air flows entering the fire room: the smaller the air change rate, the lower the oxygen concentration within the room and the lower the MLR. The oxygen concentration is the main parameter which controls the level of MLR.

\section{Air Change Rate of $8.5 h^{-1}$}

Configurations with an air change rate of $8.5 \mathrm{~h}^{-1}$ show a particular behaviour and enhance the blowing effect on the MLR.

For this air change rate, the MLRs of each scenario are different. The MLR for the 1-room scenario behaves as explained previously with 3 phases (transitory, stationary and extinction) and the MLR amplitude during the stationary phase is much lower than that in the open air. Surprisingly, the MLR for the 2-rooms scenario is very similar, in this case, to that in the open air and not to the 1-room scenario behaviour. In addition, for a short period, the MLR amplitude is even higher than that in the open air.

The analysis of the oxygen concentration also shows a difference of behaviour between the 1-room and 2-rooms scenarios. Although the oxygen concentration decreases in both cases, the concentration remains more-or-less uniform in the lower part of the room for the 1-room scenario (the two probes give nearly the same amplitude), whereas the concentration varies significantly in the 2-rooms scenario. The oxygen concentration near the pool is much higher than that in the corner of the room.

The analysis of the volumetric air flow entering the room shows a very similar behaviour to that observed with an air change rate of $4.7 \mathrm{~h}^{-1}$ (previous section). However, in that case, the air flow entering from the doorway reaches an amplitude of $2700 \mathrm{~m}^{3} \cdot \mathrm{h}^{-1}$.

The fact that, for this air change rate of $8.5 \mathrm{~h}^{-1}$, the MLR is nearly the same as that in the open air is explained by the contribution of the convective effect of the air entering the room through the doorway and blowing towards the fire. This is the result of local variations of oxygen concentration within the lower part of the fire room.

This configuration shows that the MLR depends not only on the oxygen concentration but also on the air flow motion near the pool. Both parameters have an opposite influence on the MLR. The reduction of oxygen tends to reduce the MLR whereas the air flow motion may enhance the burning rate. For the $4.7 \mathrm{~h}^{-1}$ air change rate configuration, the effect of the oxygen was predominant although the air flow through the doorway was significant. For the $8.5 \mathrm{~h}^{-1}$ air change rate configuration, the effect of the draft is probably stronger because of a sufficiently high air flow at the doorway that remains effective at the pool. It induces a locally higher oxygen level and also a blowing effect on the flame. Both enhance the burning rate. The mean velocity corresponding to this air flow is about $0.8 \mathrm{~m} \cdot \mathrm{s}^{-1}$ (see Fig. 19).

It should be noted that other tests reported in the literature (Parkes and Fleischmann [3]) show that, in some cases, the blowing effect may be strong enough to angle the flame downward and thus reduce the MLR due to a reduction of radiation feedback. In our case, the blowing effect was high enough to enhance the MLR without angling the flame downward.

\section{DISCUSSION}

The effect of air change rate on the MLR for the 1-room and 2-rooms scenarios is analyzed in Fig. 26 where the dimensionless MLR divided by the volume of the room(s) is plotted versus the air change rate. The dimensionless MLR is defined as the average MLR during the steady-state phase divided by the average MLR obtained in the open air. Test $1 \mathrm{R}_{-} \mathrm{Tr}=1.5$ is not considered, as the stationary phase is not reached. The dimensionless MLR is divided by the volume of the room(s) $\left(120 \mathrm{~m}^{3}\right.$ for 1-room tests and $240 \mathrm{~m}^{3}$ for 2-rooms tests) in order to ignore the room volume effect.

For both scenarios, the volumetric MLR increases as the air change rate increases. Two different behaviours are identified. 
For air change rates below $5 \mathrm{~h}^{-1}$, both scenarios lead to the same volumetric MLR during the stationary phase. It seems that, in this case, the two rooms behave as an equivalent single room of $240 \mathrm{~m}^{3}$. The presence of a wall and a door separating the two rooms seems to have no particular effect on the volumetric MLR observed during the stationary phase.

For air change rates above $8 \mathrm{~h}^{-1}$, the 1-room and 2-rooms scenarios show differing behaviours. The volumetric MLR in the 2-rooms scenario is much higher than in the 1-room scenario. It would appear that, for air change rates above $8 \mathrm{~h}^{-1}$, the incoming flow at the doorway induces a significant blowing effect towards the pool that increases the volumetric MLR. In this case, the 2-rooms scenario is no longer equivalent to a 1-room scenario with a room volume of $240 \mathrm{~m}^{3}$ due to this additional blowing effect. Nevertheless, this effect depends on the characteristics of the doorway and its distance from the pool fire. It should be noted that, for other geometrical configurations (e.g. variation of the pool fire distance from the doorway), the blowing effect due to the open door could have been different (Parkes and Fleischmann [3]).

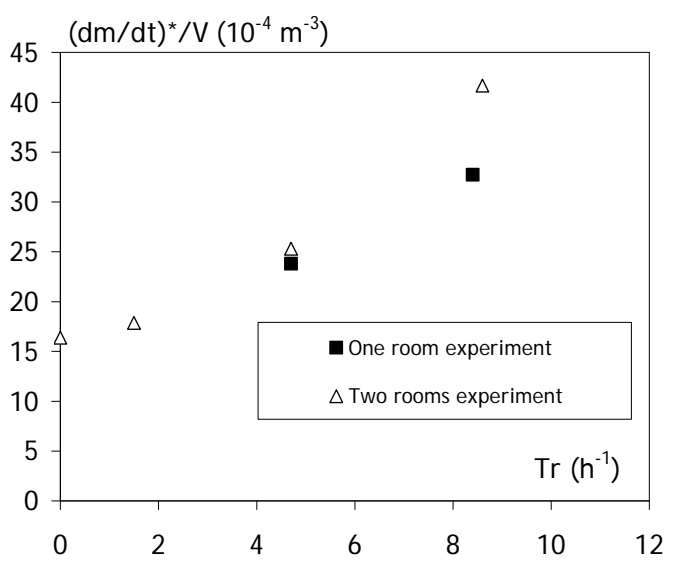

Fig. 26. Effect of the air change rate on the volumetric MLR

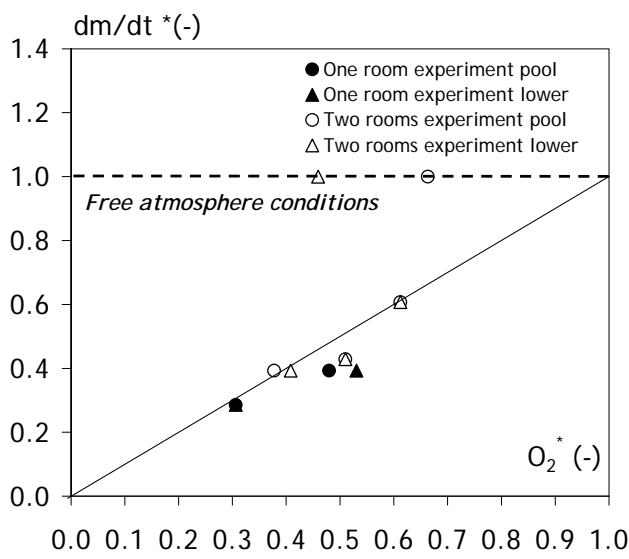

Fig. 27. Effect of the dimensionless oxygen concentration on the dimensionless MLR

From test data, the relation between the MLR and the oxygen concentration near the pool can be investigated. For all tests, the dimensionless average MLR during the stationary phase and the corresponding dimensionless oxygen concentration are correlated. Fig. 27 shows the dimensionless MLR versus a dimensionless oxygen concentration. The results show a linear relation between the two variables as observed by Peatross and Beyler [10]. The 1-room and 2-rooms tests show a linear dependency between the MLR and the oxygen concentration. Nevertheless, the 2-rooms test with an air change rate of $8.6 \mathrm{~h}^{-1}$ does not follow the same trend. The MLR is equal to that in the open air although the oxygen concentration near the pool is much lower than $21 \%_{\mathrm{vol}}$.

These observations confirm that there are two different behaviours for the MLR. Below an air change rate of $5 \mathrm{~h}^{-1}$, the MLR depends mainly on the oxygen concentration within the fire room and above $8 \mathrm{~h}^{-1}$, the blowing effect of the draft at the doorway needs to be considered.

\section{CONCLUSION}

This paper presents a study of the behaviour of the mass loss rate from a new set of large scale tests on a pool fire in confined and mechanically-ventilated multi-room scenarios. Two typical scenarios are investigated: the 1-room configuration and the 2-roomss configuration with an open doorway between the two rooms.

For both scenarios, the variation of the mass loss rate (MLR) with time shows a common behaviour: an initial transitory phase, where the MLR varies with time, a second phase during which the MLR remains steady (nearly constant for some tests) and the extinction phase.

A comparison between the two scenarios shows that the MLR for 1-room tests is much lower than that of 2 -rooms tests for the same air change rate. This result has an important safety implication, given that the opening of a door during a fire is a possible scenario. For both confined fire scenarios, the increase in the air change rate contributes to an increased MLR. One 2-rooms scenario test shows that, for a sufficiently 
high air change rate, the air flow entering into the fire room through the open doorway enhances the MLR due to a significant blowing effect (locally higher oxygen level and convective effect on the flame).

The analysis illustrates that the MLR depends, among others, on two opposing effects: the oxygen concentration near the pool and the blowing effect towards the pool. For most tests, the effect of the oxygen concentration is predominant and the MLR varies linearly with the change of oxygen concentration. For one of the 2-rooms scenario tests, the blowing effect seems to be predominant and the MLR is identical to that in the open air albeit that the oxygen concentration is below $21 \%_{\mathrm{vol}}$. This large-scale test campaign confirms that the air flow around the pool is an important parameter to predict the MLR. Nevertheless, the contribution of radiation on the pool could be an important parameter and merits further study.

This analysis also shows very similar results to those observed with a door connecting to the open. A future study could investigate the effect, for the 2-rooms scenario, of the confinement of the second room and, in particular, the effect of air vitiation on the incoming air flow to the fire room and thus on the mass loss rate.

\section{REFERENCES}

[1] Zukoski E., Kubota T., Experimental study of environment and heat transfer in a room fire, mixing in doorway flows and entrainment in fires plumes, NIST Report NPS-GCR-85-493, 1985.

[2] Nakaya I., Tanaka T., Yoshida M., Steckler K., Doorway flow induced by a propane fire, Fire Safety Journal, 10, (1985), pp185-195, doi:10.1016/0379-7112(86)90015-9.

[3] Parkes A.R., Fleischmann C.M., The impact of location and ventilation on pool fire in a compartment, Fire safety science proceedings of the eighth international symposium, pp1289$1300,2005$.

[4] Bryant R.A., Particle image velocimetry, Measurement of buoyancy induced, Flow through a doorway, NIST Report NISTIR 7252, 2005.

[5] Utiskul Y., Quintiere J.G., Rangwala A.S., Ringwelski B.A., Wakatsuki K., Naruse T., Compartment fire phenomena under limited ventilation, Fire safety journal, 40, pp. 367-390, 2005, doi:10.1016/j.firesaf.2005.02.002.

[6] Hamins A., Yang J.C., Kashiwagi T., A global model for predicting the burning rates of liquid pool fires, NIST Report NISTIR 6381, 1999.

[7] Bundy M., Hamins A., Johnsson E.L., Kim S.C., Ko G.H., Lenhert D.B., Measurements of heat and combustion products in reduced-scale ventilation-limited compartment fires, NIST Technical Note 1483, 2007.

[8] Pretrel H., Querre P., Forestier M., Experimental study of burning rate behaviour in confined and ventilated fire compartments, Fire safety science proceedings of the eighth international symposium, 2005.

[9] McCaffrey B.J., Heskestad G., A robust bidirectional low-velocity probe for flame and fire application, Combustion and Flame, Vol. 26, No. 1, pp. 125-127, 1976, doi:10.1016/00102180(76)90062-6.

[10] Peatross M.J., Beyler C.L., Ventilation effects on compartment fire characterization, Fire safety science, Proceedings of the fifth international symposium, pp. 403-414, 1997. 